\title{
Integrative Pattern of Vasomotor Efficiency in SHR During Ontogenesis
}

\author{
M. GEROVÁ, F. KRISTEK \\ Institute of Normal and Pathological Physiology, Centre of Excellence for Cardiovascular \\ Research, Slovak Academy of Sciences, Bratislava, Slovak Republic
}

Received May 31, 2007

Accepted July 11, 2007

On-line October 11, 2007

\begin{abstract}
Summary
Numerous studies concerning the cardiovascular system in SHR often yield controversial data. The background of this diversity has various roots, ranging from different vascular segments or areas studied up to the different age of experimental animals. Our study aimed to follow the BP as an integrated response of vascular system. This approach was justified since stabilized cardiac output in SHR was proved till 1 year of age. The groups of male SHR (aged 3, 5, 9, 17 and 52 weeks) and age-matched Wistar rats were used. Significant basal BP difference between SHR and Wistar rats was found at 9 weeks of age and continued till the age of 52 weeks, reaching $189.6 \pm 11.9 \mathrm{~mm} \mathrm{Hg}$ in SHR and $117.3 \pm 6.9 \mathrm{~mm} \mathrm{Hg}$ in Wistar rats $(P<0.01)$. The significant difference in BP increase to two doses of noradrenaline $(0.1 \mu \mathrm{g}$ and $1 \mu \mathrm{g}$ ) between SHR and control rats was also found at the age of 9 weeks. At 52 weeks the BP increment to two doses of noradrenaline was in SHR $19.7 \pm 2.0 \mathrm{~mm} \mathrm{Hg}$ and $60.5 \pm 3.9 \mathrm{~mm} \mathrm{Hg}$ and in Wistar rats $7.4 \pm 1.9 \mathrm{~mm} \mathrm{Hg}$ and $40.5 \pm 3.2 \mathrm{~mm} \mathrm{Hg}$ $(\mathrm{P}<0.01)$. The hypotensive response to acetylcholine $(0.1 \mu \mathrm{g}$, $1 \mu \mathrm{g}$ and $10 \mu \mathrm{g}$ ) in SHR was enhanced at 17 weeks of age only and this amplification persisted till the age of 52 weeks. In 52week-old SHR the hypotensive response to three doses was $69.9 \pm 10.2 \mathrm{~mm} \mathrm{Hg}, 87.5 \pm 11.8 \mathrm{~mm} \mathrm{Hg}$ and $103.4 \pm 10.6 \mathrm{~mm} \mathrm{Hg}$, while in Wistar rats it was $37.4 \pm 4.2 \mathrm{~mm} \mathrm{Hg}(P<0.01), 62.3 \pm 3.5$ $\mathrm{mm} \mathrm{Hg}(\mathrm{P}<0.01)$ and $73.5 \pm 2.8 \mathrm{~mm} \mathrm{Hg}(\mathrm{P}<0.05)$. In conclusion, the efficiency of cardiovascular system of SHR to respond to noradrenaline was already enhanced from 9 weeks of age, whereas the response to acetylcholine was not augmented before the age of 17 weeks.
\end{abstract}

\section{Key words}

SHR • Ontogenesis • Noradrenaline • Acetylcholine • Vascular system

\section{Corresponding author}

Mária Gerová, Institute of Normal and Pathological Physiology, Slovak Academy of Sciences, Sienkiewiczova 1, 81371 Bratislava, Slovak Republic. E-mail: Maria.gerova@savba.sk

\section{Introduction}

Spontaneously hypertensive rats (SHR) are one of the most studied experimental models in cardiovascular pathology. Indeed, high blood pressure (BP) is generally accepted as one of the major risk factors of cardiovascular diseases. Discussion has been running on how far the experimental model of SHR, developed on genetical basis, does meet the human essential hypertension. Differences discussed include body weight, occurrence of atherosclerosis, and before all, differences of prostaglandin mechanisms controlling renal circulation. All these issues require cautious considering the similarity of SHR and essential hypertension (Folkow et al. 1970, McGiff and Quilley 1981, Trippodo and Frohlich 1981, Labat et al. 2006).

Dozens of studies aimed to reveal and to identify the control mechanisms and the tools involved in maintaining the high blood pressure in SHR. They comprise sympathetic nervous system (de Champlain et al. 1976, Folkow 1982, Scott and Pang 1983), reninangiotensin system (Freslon and Giudicelli 1983, Wu and Berecek 1993), natriuretic peptides (Gutkowska et al. 1986), aldosterone (Willis and Bauer 1978), and relevant genes (Rapp 2000).

Numerous studies were devoted to the geometry of resistant and conduit arteries, which the above mentioned dysbalanced control mechanisms are operating on, and which are carrying the load of high blood pressure. These studies confirm the old finding of Johnson (1868) in renal hypertension, later reaffirmed by Folkow et al. (1970) that altered geometry of vessels, namely the increase in wall thickness and decrease of 
inner diameter in resistant arteries accompany the high blood pressure in SHR.

As far as the increase of wall thickness is concerned, both components - cellular and non-cellular were suggested to participate (Lee et al. 1983, Kristek 1997). Concerning smooth muscle, the experimental results varied from hypertrophy and hyperplasia up to apoptosis (Lee et al. 1983, Dickhout and Lee 2000, Rizzoni et al. 2000).

Morphological composition of the respective vessel wall is decisive for its functional effectiveness, i.e. the range of constriction and relaxation ability. Like the composition of vessels, the variation in vasomotor responses to stimuli of individual vessels in vitro, or perfused areas in vivo were demonstrated in SHR (Lais and Brody 1978, Tominaga et al. 1994, Yamazaki et al. 1999, Bund 2001, Gerová et al. 2005). The variability of these results might reflect the fact that (i) animals used in experiments were in various phases of ontogenetic development (suckling, weaning, juveniles, adults), and (ii) various vascular portions were studied.

Blood pressure integrates the above structural and functional parameters in the whole vascular tree. This idea holds true if efficiency of the heart is stabilized. The heart weight increases with age in SHR more markedly than in Wistar rats. However, cardiac output is stabilized from 8 to 52 weeks as was demonstrated by Albrecht et al. (1972) and Pfeffer et al. (1979).

The following experiments aimed to evaluate the integrative blood pressure responses in SHR and control Wistar rats to basal constricting and relaxing stimuli during key developmental stages.

\section{Methods}

Male spontaneously hypertensive rats and control Wistar rats were used for the experiments. Procedures and the experimental protocol were approved by the Animal Care Committee of the Slovak Academy of Sciences.

According to accepted critical ontogenetic periods in rats (Albrecht et al. 1972, Zicha and Kuneš 1999) following age groups were selected:

- Group 1 - end of the suckling period - 3 weeks of age: the group consisted of 7 SHR and 8 Wistar rats.

- Group 2 - end of the weaning period - 5 weeks of age: the group consisted of 7 SHR and 6 Wistar rats.

- Group 3 - early adult age (juveniles) - 9 weeks of age: the group consisted of 7 SHR and 7 Wistar rats.
- Group 4 - stabilized adult age - 17 weeks of age: the group consisted of $7 \mathrm{SHR}$ and 10 Wistar rats.

- Group 5 - advanced adult age - 52 weeks of age: the group consisted of 6 SHR and 5 Wistar rats.

Systolic blood pressure of conscious rats in the above groups was measured using tail plethysmography.

For anesthesia, Narkamon in the dose 0.25 $\mathrm{ml} / 100 \mathrm{~g}$ b.w., and Rometar in the dose $0.1 \mathrm{ml} / 100 \mathrm{~g} \mathrm{b.w}$. were used, both administered i. p. Right jugular vein was cannulated for administration of the respective drugs. Immediately, heparin in a dose of 25 i.u., was injected. Right carotid artery was cannulated and connected to Stattham pressure transducer. Physioscript Schwarzer was used for recording the blood pressure. Changes of mean arterial pressure (MAP) were evaluated after drug administration.

After stabilization period lasting about $10 \mathrm{~min}$, noradrenaline in the doses $0.1 \mu \mathrm{g}$ and $1.0 \mu \mathrm{g}$, dissolved constantly in $0.1 \mathrm{ml}$ of physiological salt solution, was administered into the jugular vein over a constant period of $10 \mathrm{~s}$. Likely, acetylcholine in the doses $0.1 \mu \mathrm{g}, 1 \mu \mathrm{g}$, and $10 \mu \mathrm{g}$ was administered into the jugular vein. Both above drugs were administered in a random order. Individual stimuli were applied in 10-15 min interval, after BP returned to basal level and was stabilized.

Noradrenaline and acetylcholine were from Sigma (Germany), heparin from Zentiva (Czech Republic), Narkamon and Rometar for anesthesia were from Spofa (Czech Republic).

The blood pressure values were expressed as means \pm S.E.M. ANOVA and Bonferroni t-test was used for statistical evaluation. $\mathrm{P}<0.05$ values were considered significant.

\section{Results}

\section{Basal BP in individual critical ontogenetic periods}

At the end of suckling period ( 3 weeks of age) the BP values in SHR reached $84.2 \pm 6.3 \mathrm{~mm} \mathrm{Hg}$ and in Wistar rats $83.3 \pm 1.4 \mathrm{~mm} \mathrm{Hg}$ (Fig. 1). At the end of weaning period ( 5 weeks of age) the BP value found in SHR were $105.0 \pm 3.4 \mathrm{~mm} \mathrm{Hg}$, and $100.0 \pm 2.6 \mathrm{~mm} \mathrm{Hg}$ in Wistar rats, the difference being not significant. The BP value (123.7 $\pm 5.3 \mathrm{~mm} \mathrm{Hg}$ ) measured in juvenile SHR ( 9 weeks of age) was already significantly higher than blood pressure of Wistar rats $(100.2 \pm 3.2 \mathrm{~mm} \mathrm{Hg})(\mathrm{P}<0.01)$. A pronounced BP elevation (176.6 $\pm 9.6 \mathrm{~mm} \mathrm{Hg}$ ) was found in adult SHR aged 17 weeks, whereas in age-matched Wistar rats BP reached 107.6 $\pm 3.6 \mathrm{~mm} \mathrm{Hg}$ only $(\mathrm{P}<0.01)$. In both $\mathrm{SHR}$ and 


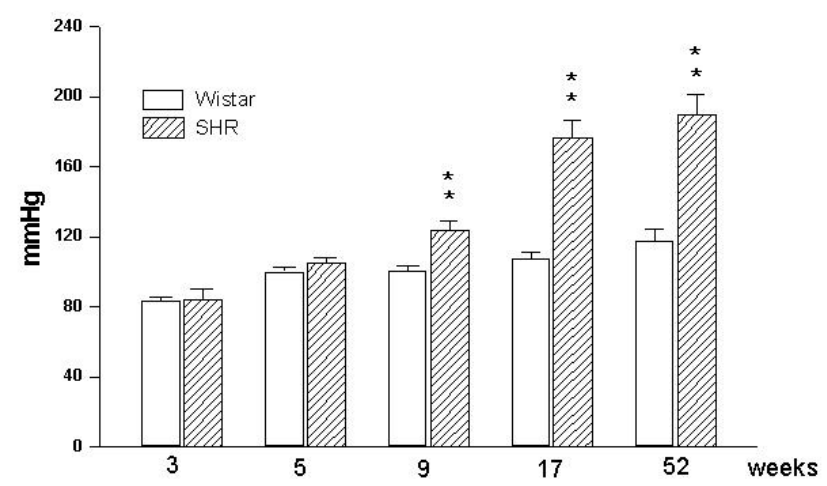

Fig. 1. Basal systolic BP in individual critical ontogenetic periods.

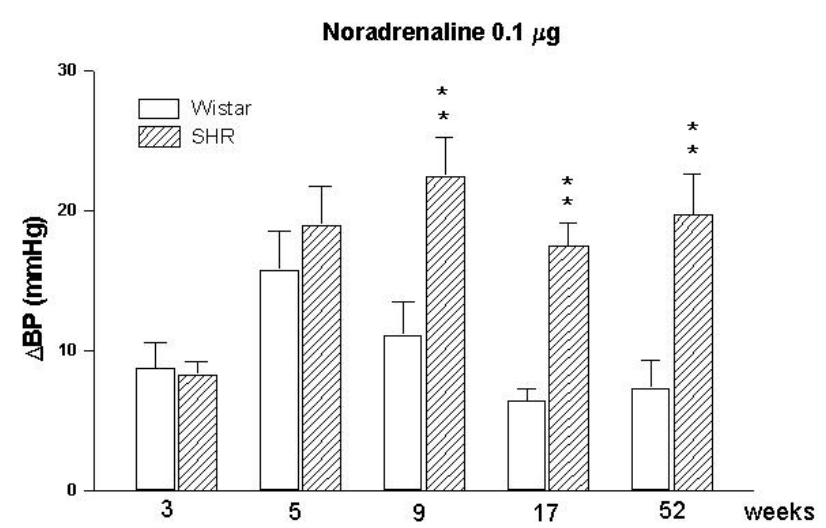

Fig. 2. $B P$ increase induced by noradrenaline $0.1 \mu \mathrm{g}$ i.v. in individual critical ontogenetic periods.

Wistar rats BP values found in 17-week-old animals were similar to those obtained at the age of 52 weeks (SHR $189.6 \pm 11.9 \mathrm{~mm} \mathrm{Hg}$; Wistar rats $117.3 \pm 6.9 \mathrm{~mm} \mathrm{Hg}$; $\mathrm{P}<0.01$ ) (Fig. 1).

Blood pressure response to noradrenaline in individual critical ontogenetic periods

Figure 2 demonstrates the value of mean BP increase elicited by $0.1 \mu \mathrm{g}$ noradrenaline i.v. in particular age groups of SHR and Wistar rats. In 3-week-old rats the administration of noradrenaline caused similar BP increment in SHR $(8.3 \pm 0.9 \mathrm{~mm} \mathrm{Hg})$ and Wistar rats $(8.8 \pm 1.8 \mathrm{~mm} \mathrm{Hg})$. BP responses to the same noradrenaline dose in 5-week-old SHR $(19.0 \pm 2.8 \mathrm{~mm} \mathrm{Hg})$ and Wistar rats $(15.8 \pm 2.8 \mathrm{~mm} \mathrm{Hg})$ indicated a tendency to differ. Blood pressure increase of SHR aged 9 weeks was $22.5 \pm 2.7$ $\mathrm{mm} \mathrm{Hg}$, which was significantly higher in comparison to Wistar rats $(11.2 \pm 2.3 \mathrm{~mm} \mathrm{Hg})(\mathrm{P}<0.01)$. The response to noradrenaline in 17-week-old SHR $(17.5 \pm 1.6 \mathrm{~mm} \mathrm{Hg})$ was remarkably higher than that seen in Wistar rats $(6.5 \pm 0.8$ $\mathrm{mm} \mathrm{Hg})(\mathrm{P}<0.01)$. At the age of 52 weeks SHR responded to this noradrenaline dose by $19.7 \pm 2.0 \mathrm{~mm} \mathrm{Hg}$ and Wistar

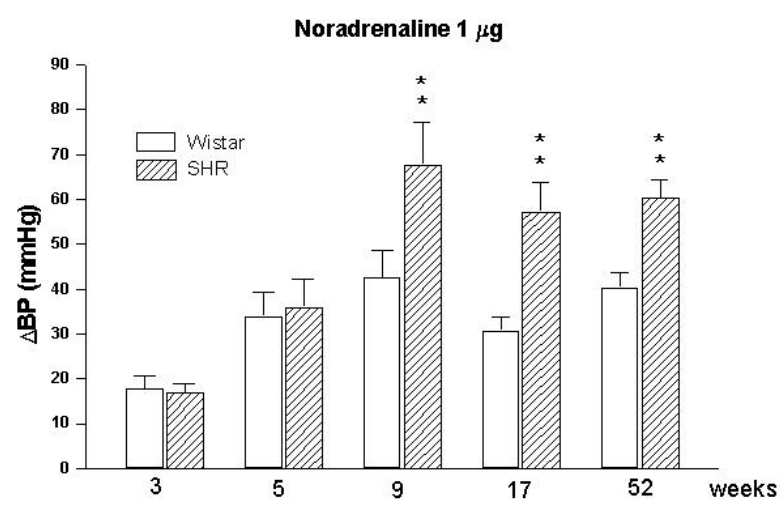

Fig. 3. $B P$ increase induced by noradrenaline $1 \mu \mathrm{g}$ i.v. in individual critical ontogenetic periods.

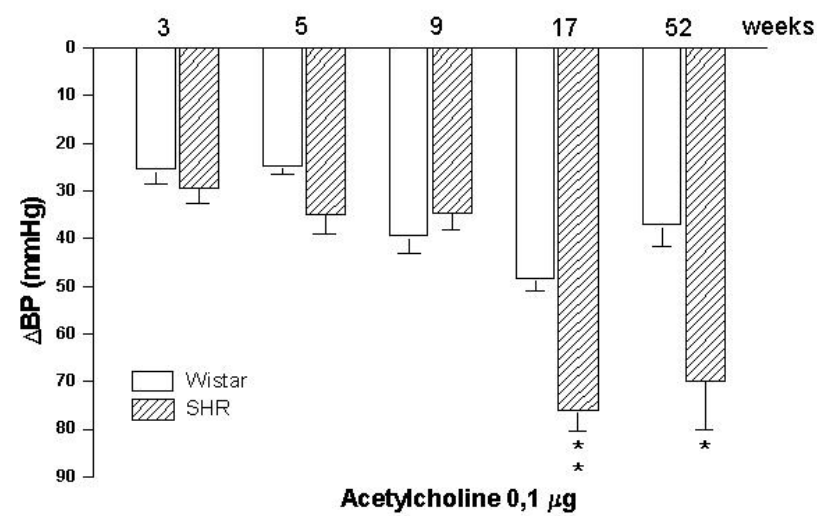

Fig. 4. $B P$ decrease induced by acetylcholine $0.1 \mu \mathrm{g}$ i.v. in individual critical ontogenetic periods.

rats by $7.4 \pm 1.9 \mathrm{~mm} \mathrm{Hg}(\mathrm{P}>0.01)$, again the $\mathrm{BP}$ rise was significantly higher in SHR.

Figure 3 shows the responses to $1.0 \mu \mathrm{g}$ noradrenaline i.v. in SHR and Wistar rats of particular age groups. Noradrenaline elicited in SHR and Wistar rats aged 3 weeks a similar BP increase, i.e. 16.9 \pm 1.9 $\mathrm{mm} \mathrm{Hg}$ and $17.8 \pm 2.8 \mathrm{~mm} \mathrm{Hg}$, respectively. In 5-weekold SHR and Wistar rats BP response amounted 36.0 06.4 $\mathrm{mm} \mathrm{Hg}$ and $34.0 \pm 5.4 \mathrm{~mm} \mathrm{Hg}$, respectively, values close each other. SHR aged 9 weeks responded to $1.0 \mu \mathrm{g}$ noradrenaline by a higher BP increase $(67.8 \pm 9.5 \mathrm{~mm} \mathrm{Hg})$ than Wistar rats $(42.6 \pm 6.25 \mathrm{~mm} \mathrm{Hg})(\mathrm{P}<0.01)$. At the age of 17 weeks SHR responded to $1.0 \mu \mathrm{g}$ noradrenaline and more than Wistar rats $(57.4 \pm 6.5 \mathrm{~mm} \mathrm{Hg}$ vs. $30.8 \pm 3.07$ $\mathrm{mm} \mathrm{Hg}) \quad(\mathrm{P}<0.01)$. BP increase elicited by $1.0 \mu \mathrm{g}$ noradrenaline in 52-week-old SHR was $60.5 \pm 3.9 \mathrm{~mm} \mathrm{Hg}$ and in age-matched Wistar rats $40.5 \pm 3.2 \mathrm{~mm} \mathrm{Hg}$ $(\mathrm{P}<0.01)$.

Blood pressure response to acetylcholine in individual critical ontogenetic periods

Figure 4 represents BP changes after $0.1 \mu \mathrm{g}$ 


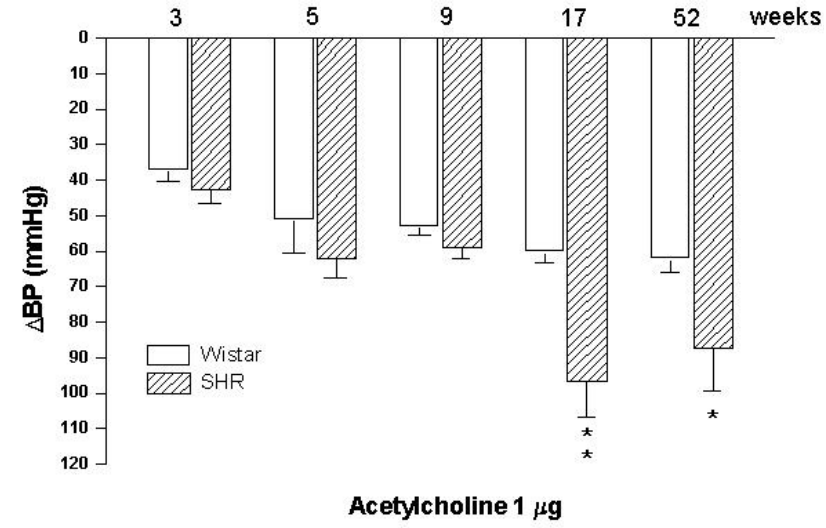

Fig. 5. BP decrease induced by acetylcholine $1.0 \mu \mathrm{g}$ i.v. in individual critical ontogenetic periods.

acetylcholine i.v. in SHR and Wistar rats of particular age groups. Three-week-old SHR responded to this acetylcholine dose by mean BP decrease of $29.4 \pm 3.3$ $\mathrm{mm} \mathrm{Hg}$ and Wistar rats by $25.8 \pm 2.8 \mathrm{~mm} \mathrm{Hg}$. In 5 -weekold SHR mean BP was reduced by $35.1 \pm 4.3 \mathrm{~mm} \mathrm{Hg}$ and in Wistar rats by $25.0 \pm 1.4 \mathrm{~mm} \mathrm{Hg}$. SHR aged 9 weeks responded by BP decrease of $34.6 \pm 3.5 \mathrm{~mm} \mathrm{Hg}$ and Wistar rats by $39.8 \pm 3.8 \mathrm{~mm} \mathrm{Hg}$. However, BP fall in 17week-old SHR was $76.2 \pm 4.0 \mathrm{~mm} \mathrm{Hg}$, whereas that of Wistar rats only $48.6 \pm 2.5 \mathrm{~mm} \mathrm{Hg}(\mathrm{P}<0.01)$. Similar difference was found in SHR aged 52 weeks, in which acetylcholine induced BP decrease of $69.9 \pm 10.2 \mathrm{~mm} \mathrm{Hg}$, but only $37.4 \pm 4.2 \mathrm{~mm} \mathrm{Hg}$ was observed in age-matched Wistar rats $(\mathrm{P}<0.01)$.

Figure 5 depicts BP reduction following i.v. administration of $1.0 \mu \mathrm{g}$ acetylcholine in SHR and Wistar rats of particular age groups. Three-week-old SHR responded by $42.7 \pm 3.8 \mathrm{~mm} \mathrm{Hg}$ and Wistar rats by $37.4 \pm 3.0 \mathrm{~mm} \mathrm{Hg}$. At the age of 5 weeks BP response of SHR and Wistar rats was $62.0 \pm 5.7 \mathrm{~mm} \mathrm{Hg}$ and $51.3 \pm 9.2$ $\mathrm{mm} \mathrm{Hg}$, respectively. BP decrease in 9-week-old SHR and Wistar rats was $59.1 \pm 3.1 \mathrm{~mm} \mathrm{Hg}$ and $53.1 \pm 2.4$ $\mathrm{mm} \mathrm{Hg}$, respectively. However, at the age of 17 weeks BP was decreased by $96.6 \pm 10.1 \mathrm{~mm} \mathrm{Hg}$ in SHR and only by $60.4 \pm 2.9 \mathrm{~mm} \mathrm{Hg}$ in Wistar rats $(\mathrm{P}<0.01)$. SHR aged 52 weeks responded by $87.5 \pm 11.8 \mathrm{~mm} \mathrm{Hg}$ and Wistar rats by $62.3 \pm 3.5 \mathrm{~mm} \mathrm{Hg}(\mathrm{P}<0.01)$.

Figure 6 shows BP responses to $10 \mu \mathrm{g}$ i.v. in SHR and Wistar rats of particular age groups. Threeweek-old SHR and Wistar rats responded by $51.6 \pm 2.9$ $\mathrm{mm} \mathrm{Hg}$ and $44.5 \pm 2.3 \mathrm{~mm} \mathrm{Hg}$, respectively. Five-week-

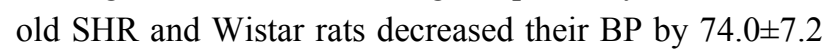
$\mathrm{mm} \mathrm{Hg}$ and $66.5 \pm 6.9 \mathrm{~mm} \mathrm{Hg}$, respectively. At the age of 9 weeks BP decrease in SHR $(65.6 \pm 6.1 \mathrm{~mm} \mathrm{Hg})$ was still close to that of Wistar rats $(62.9 \pm 3.9 \mathrm{~mm} \mathrm{Hg})$. However,

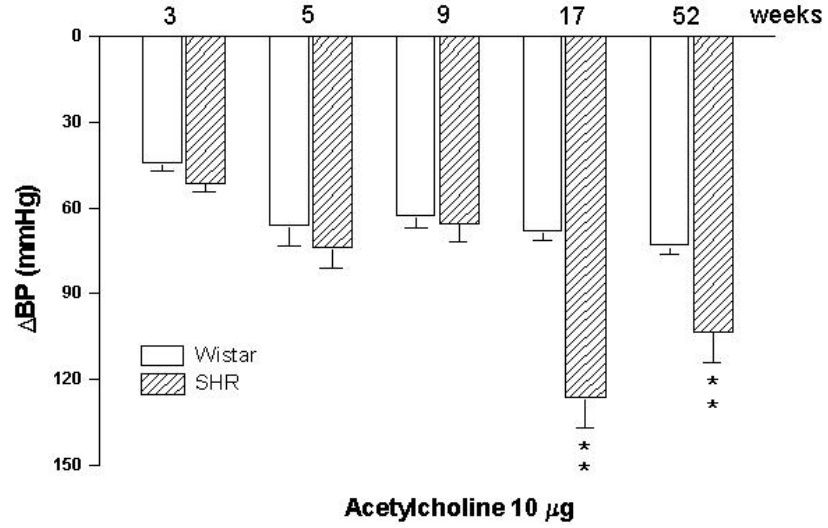

Fig. 6. $B P$ decrease induced by acetylcholine $10 \mu \mathrm{g}$ i.v. in individual critical ontogenetic periods.

BP decrease in 17-week-old SHR $(126.5 \pm 10.3 \mathrm{~mm} \mathrm{Hg})$ was more pronounced than that of Wistar rats $(68.5 \pm 2.7$ $\mathrm{mm} \mathrm{Hg})(\mathrm{P}<0.01)$. 52-week-old SHR responded to this acetylcholine dose by a greater BP decrease $(103.4 \pm 10.6$ $\mathrm{mm} \mathrm{Hg})$ than Wistar rats $(73.5 \pm 2.8 \mathrm{~mm} \mathrm{Hg})(\mathrm{P}<0.05)$.

\section{Discussion}

The blood pressure of 3- and 5-week-old SHR, i.e. till the end of weaning period, did not differ from that found in the age-matched Wistar rats. However, a significant difference in the blood pressure was found between 9-week-old SHR and Wistar rats. High BP in SHR was maintained till the age of 52 weeks.

Blood pressure response of 3-week-old sucklings to noradrenaline administered in two doses $(0.1 \mu \mathrm{g}$ and $1 \mu \mathrm{g}$ ), increased dose-dependently in the same range in SHR and control Wistar rats. Similarly, no difference in BP response to noradrenaline was found in 5-week-old weanling SHR and Wistar rats.

However, the juvenile SHR aged 9 weeks, responded to both noradrenaline doses by an augmented BP increment in comparison to Wistar rats. As was mentioned above, this age group of SHR is already characterized by a significantly higher value of basal blood pressure.

The amplified BP response to noradrenaline persisted in adult 17-week-old SHR, and a similar amplified pattern of BP response to noradrenaline was even observed in 52-week-old SHR. Calculation the responses in relation to basal pressure yielded similarly amplified value in SHR.

Hypotensive responses to increasing doses of acetylcholine $(0.1 \mu \mathrm{g}, 1 \mu \mathrm{g}$, and $10 \mu \mathrm{g})$ rose dosedependently in 3-week-old SHR and Wistar rats, but no 
difference was found between the responses of the two strains studied. Similarly, no difference in hypotensive response to the above doses of acetylcholine was found in 5- or 9-week-old SHR and Wistar rats. A significantly amplified hypotension to all three doses of acetylcholine was found only in 17- and 52-week-old SHR when compared to age-matched Wistar rats. On the other hand, a significantly higher basal blood pressure and a significantly amplified response to noradrenaline were already found in 9-week-old SHR compared to Wistar rats.

It is generally accepted that in SHR blood pressure starts to increase after 5 weeks of age and achieves a significantly elevated value in comparison to Wistar rats (Zicha and Kuneš 1999). There is also a common agreement as far as the biophysical background of high blood pressure is concerned. The geometry of resistant vessels, namely increased wall/lumen ratio, was confirmed in several studies (Folkow et al. 1970, Mulvany and Aalkjaer 1990, Bund 2001). However, there is not a unified view on the component(s) responsible for wall thickness increase, although the respective components could affect vasomotor efficiency of vascular system. Dickhout and Lee (2000) found a difference in the length of smooth muscle cells in mesenteric vessels even in 4-week-old offspring of spontaneously hypertensive rats. Lee et al. (1983) demonstrated that in mesenteric area, in particular in muscular arteries and arterioles, there was hypertrophy and hyperplasia of smooth muscle cells in 12-week-old SHR.

Brilla et al. (1991) and Weber (2000) confirmed the hypertrophy and hyperplasia of smooth muscle cells in media of intramural coronary arteries in adult SHR with cardiac hypertrophy. They drew attention to the contribution of non-cellular component to the wall thickness increase. Recent analytical studies, using the point counting method, yield further reliable data on increase of non-cellular and/or extracellular matrix in conduit vessel wall of adult SHR and other hypertensive models (Kristek 1997, Kristek et al. 1996). Thus, the data indicating the contribution of extracellular matrix, beside the media smooth muscle, to vascular wall thickness have to be faced up.

Fibroblasts might be hypothetically considered as a source of extracellular matrix. This hypothesis is supported by following points: (i) sympathetic nervous system has been considered as one of the basic mechanisms responsible for the high blood pressure in SHR (de Champlain et al. 1976, Scott and Pang 1983,
Lee et al. 1986, Dominiak et al. 1987, Head 1989), (ii) fibroblasts in vascular wall have much close apposition to adrenergic nerve terminals than to vascular smooth muscle (Kristek and Gerová 1987), and (iii) fibroblasts are endowed with adrenergic receptors (Azevedo and Soares-da-Silva 1981). However, this hypothesis remains open as the effect of sympathetic nervous system on function of fibroblasts is not fully known.

The other source of extracellular matrix increase in vascular wall might be vascular smooth muscle cell itself, because it can undergone a transformation of phenotype from contractile to synthetic type and might also participate in production of extracellular matrix and thereby contribute to wall thickness increase. The question of contractility alterations due to change of phenotype of vascular smooth muscle is also a challenging issue.

As far as the contractile efficiency is concerned, Lais and Brody (1978) provided the evidence on the hyperresponsiveness to noradrenaline in hindquarter vascular bed of 3-week-old SHR. Similar results were obtained by Dickhout and Lee (2000) in mesenteric vessels of SHR aged 3-4 weeks compared to age-matched control Wistar rats. However, these results on mesenteric arteries were not confirmed by Bund (2000), who also found no difference in basal myogenic tone of femoral artery from SHR and control Wistar rats aged 4-5 months.

Our experiments carried out in rats aged 3 to 52 weeks demonstrated the altered development of vascular constriction ability in SHR. In SHR aged 3 to 5 weeks BP response to noradrenaline was comparable to that of Wistar rats, but from the age of 9 to 52 weeks SHR responded to noradrenaline by a significantly amplified BP increase.

As far as acetylcholine-induced relaxation is concerned, Pourageaud and Freslon (1992) found a reduced relaxation to acetylcholine in both mesenteric arteries and coronary arteries of SHR. They stated that this was due to functional alteration of the respective endothelium, whereas the efficiency of smooth muscle cells did not differ from that of Wistar rats. Endotheliumdependent relaxation was found to be reduced in conduit vessels of SHR - aorta (Lüscher and Vanhoutte 1986) and cerebral arteries (Tesfamariam and Halpern 1988). Qiu et al. (1998) also found an attenuation of flowinduced dilation, generally accepted as NO underlying phenomenon. 
Contrary to the above studies carried out in vitro on isolated arteries, the experimental studies performed in vivo on anesthetized SHR demonstrated enhanced BP decrease to acetylcholine administration in comparison to control Wistar rats. Granstam et al. (1998) reported a significantly enhanced hypotensive response of systemic BP to acetylcholine in 12-week-old SHR. This paper confirmed the earlier findings of Yamazaki et al. (1991) who reported mildly amplified hypotension induced by acetylcholine in SHR aged 6 and 13 weeks. However, these data are at variance with the experiments of Tominaga et al. (1994) who described decreased BP response in 4- and 8-month-old SHR after acetylcholine injection.

Our results obtained in SHR aged 3, 5, 9, 17 and 52 weeks proved sufficient efficiency of vasodilatation mechanism as reflected by BP decrease to three increasing doses of acetylcholine from the first weeks of life. Nevertheless, the response to acetylcholine was amplified only in SHR aged 17 and 52 weeks. Moreover, another study on 10-week-old SHR treated for six weeks with NO donors (Gerová et al. 2005) also yielded an enhanced hypotension after acetylcholine compared to Wistar control rats. Mildly amplified response to acetylcholine was revealed not only in rats, but also in aortas of dog puppies aged 6 weeks (Török and Gerová 1996).

It is noteworthy that both the significant increase of basal BP and the significantly augmented constrictor response to noradrenaline were found in 9-week-old
SHR. On the other hand, significant enhancement of acetylcholine-induced hypotension was found only in 17-week-old SHR. The above time sequence of vasomotor activities reflected by $\mathrm{BP}$ elevation raises the question whether the increased vasoconstrictor activity of sympathetic nervous system and renin-angiotensin system does activate NO synthase with a consequent increase of endothelial NO production - as a process of adaptation.

It is evident from this evaluation of the blood pressure integrative response in SHR and Wistar rats that both vasoconstriction to noradrenaline and vasorelaxation to acetylcholine do not reveal signs of failure of the cardiovascular system from 3 up to 52 weeks of rat age. Contrary, the efficacy of vascular system to respond to vasomotor stimuli seems to be ready and even higher suggesting the adaptation process. Nevertheless, these surprising findings maintain the challenge for the intensive studies of clinical physiology and pathophysiology of human hypertension.

\section{Conflict of Interest}

There is no conflict of interest.

\section{Acknowledgements}

The study was supported by VEGA Grant 2/6139/27, Slovak Republic. The authors express gratitude to L. Kosnáčová for technical assistance, I. Hanáčková for reliable animal care and $\mathrm{K}$. Šoltésová for secretarial work, M. Majerčíková for English revision.

\section{References}

ALBRECHT I, VÍZEK M, K ̌̌EČEK J: The hemodynamics of the rat, with special reference to the age factor in the development of hypertension. In: Spontaneous Hypertension: Its Pathogenesis and Complications. K. Okamoto (ed), Igaku Shoin, Tokyo, 1972, pp 121-127.

AZEVEDO I, SOARES-DA-SILVA: Are fibroblasts adrenergically innervated cells? Blood Vessels 18: 330-332, 1981.

BRILLA CG, JANICKI JS, WEBER KT: Impaired diastolic function and coronary reserve in genetic hypertension: role of interstitial fibrosis and medial thickening of intramyocardial coronary arteries. Circ Res 69: 107-115, 1991.

BUND SJ: Contractility of resistance arteries of spontaneously hypertensive rats related to their media: lumen ratio. J Hypertens 18: 1223-1231, 2000.

BUND SJ: Spontaneously hypertensive rat resistance artery structure related to myogenic and mechanical properties. Clin Sci 101: 385-393, 2001.

DE CHAMPLAIN J, FARLEY J, COUSINEAU D, VAN AMERINGEN MR: Circulation catecholamine levels in human and experimental hypertension. Circ Res 38: 109-114, 1976.

DICKHOUT JG, LEE RMKW: Increased medial smooth muscle cell length is responsible for vascular hypertrophy in young hypertensive rats. Am J Physiol 279: H2085-H2094, 2000.

DOMINIAK P, ELFRATH A, TRÜCK D: Biosynthesis of catecholamines and sympathetic outflow in SHR after chronic treatment with CE blocking agents. J Cardiovasc Pharmacol 10: S122-S124, 1987. 
FOLKOW B: Physiological aspects of primary hypertension. Physiol Rev 62: 347-504, 1982.

FOLKOW B, HALLBACK M, LUNDGREN Y, WEISS L: Background of increased flow resistance and vascular reactivity in spontaneously hypertensive rats. Acta Physiol Scand 80: 93-106, 1970.

FRESLON JL, GIUDICELLI JF: Compared myocardial and vascular effects of captopril and dihydralazine during hypertension development in spontaneously hypertensive rats. Br J Pharmacol 80: 533-543, 1983.

GEROVÁ M, KRISTEK F, ČAČÁNYIOVÁ S, CEBOVÁ M: Acetylcholine and bradykinin enhance hypotension and affect the function of remodeled conduit arteries in SHR and SHR treated with nitric oxide donors. Braz J Med Biol Res 38: 959-966, 2005.

GRANSTAM S-O, GRANSTAM E, FELLSTRÖM B, LIND L: Effects of acetylcholine and nitroprusside on systemic and regional hemodynamics in hypertensive rats. Clin Exp Hypertens 20: 223-243, 1998.

GUTKOWSKA J, HORKY K, LACHANCE C, RACZ K, GARCIA R, THIBAULT G, KÜCHEL J, GENEST J, CANTIN M: Arterial natriuretic factor in spontaneously hypertensive rats. Hypertension 8 (Suppl I): I137I140, 1986.

HEAD RJ: Hypernoradrenergic innervation: its relationship to functional and hyperplastic changes in the vasculature of the spontaneously hypertensive rat. Blood Vessels 26: 1-20, 1989.

JOHNSON G: On certain points in the anatomy and pathology of Bright's disease of the kidney. II. On the influence of the minute blood vessels upon the circulation. Trans R Med Chir Soc 51: 57-78, 1868.

KRISTEK F: Different structure of coronary wall in two types of hypertension: NO deficiency and SHR. In: The Biology of Nitric Oxide, S. MONCADA, L.E. GUSTAFSSON, N.P. WIKLUND, E.A. HIGGS (eds), Portland Press, London, 1997, p 69.

KRISTEK F, GEROVÁ M: Autonomic nerve terminals in relation to contractile and non-contractile structures in the conduit coronary artery of the dog. Acta Anat 129: 149-154, 1987.

KRISTEK F, GEROVÁ M, DEVÁT L, VARGA I: Remodeling of septal branch of coronary artery and carotid artery in L-NAME treated rats. Physiol Res 45: 329-333, 1996.

LABAT C, CUNHA RS, CHALLANDE P, SAFAR ME, LACOLLEY P: Respective contribution of age, mean arterial pressure and body weight on central arterial distensibility in SHR. Am J Physiol 290: H1534-H1539, 2006.

LAIS LT, BRODY MJ: Vasoconstrictor hyperresponsiveness: An early pathogenic mechanism in the spontaneously hypertensive rat. Eur J Pharmacol 47: 177-189, 1978.

LEE RMKW, COUGHLIN MD, CHEUNG DWT: Relationship between sympathetic innervation, vascular changes and hypertension in the spontaneously hypertensive rat. J Hypertension 4 (Suppl 3): S81-S83, 1986.

LEE RMKW, FORREST JB, GARFIELD RE, DANIEL EE: Ultrastructural changes in mesenteric arteries from spontaneously hypertensive rats. Blood Vessels 20: 72-91, 1983.

LÜSCHER TF, VANHOUTTE PM: Endothelium dependent contractions to acetylcholine in the aorta of the spontaneously hypertensive rats. Hypertension 8: 344-348, 1986.

MCGIFF JC, QUILLEY CP: The rat with spontaneous genetic hypertension is not a suitable model of human essential hypertension. Circ Res 48: 455-463, 1981.

MULVANY MJ, AALKJAER C: Structure and function of small arteries. Physiol Rev 70: 921-971, 1990.

PFEFFER JM, PFEFFER MA, FISHBEIN MC, FROHLICH ED: Cardiac function and morphology with aging in the spontaneously hypertensive rat. Am J Physiol 237: H461-H468, 1979.

POURAGEAUD F, FRESLON JL: Endothelium function in resistance and coronary arteries of spontaneously hypertensive compared to WKY rats: effects of nitro-L-arginine. In: Genetic Hypertension. J. SASSARD (ed), Vol. 218, John Libbey Eurotext Ltd, 1992, pp 39-41.

QIU HY, HENRION D, BENESSIANO J, HEYMES C, TOURNIER B, LEVY BI: Decreased flow-induced dilation and increased production of cGMP in spontaneously hypertensive rats. Hypertension 32: 1098-1103, 1998.

RAPP JP: Genetic analysis of inherited hypertension in the rat. Physiol Rev 80: 135-172, 2000.

RIZZONI D, RODELLA L, PORTERI E, REZZANI R, GUELFI D, PICCOLI A, CASTELLANO M, MUIESAN ML, BIANCHI R, ROSEI EA: Time course of apoptosis in small resistance arteries of spontaneously hypertensive rats. J Hypertens 18: 885-891, 2000. 
SCOTT TM, PANG SC: The correlation between the development of sympathetic innervation and the development of medial hypertrophy in jejunal arteries in normotensive and spontaneously hypertensive rats. J Autonom Nerv Syst 8: 25-32, 1983.

TESFAMARIAM B, HALPERN W: Endothelium-dependent and endothelium-independent vasodilation in resistance arteries from hypertensive rats. Hypertension 11: 440-444, 1988.

TOMINAGA M, FUJII K, ABE I, TAKATA Y, KOBAYASHI K, FUJISHIMA M: Hypertension and ageing impair acetylcholine-induced vasodilation in rats. J Hypertens 12: 259-268, 1994.

TÖRÖK J, GEROVÁ M: Vascular responses after long-term inhibition of nitric oxide synthesis in newborn dogs. Physiol Res 45: 323-328, 1996.

TRIPPODO NC, FROHLICH ED: Similarities of genetic (spontaneous) hypertension. Man and rat. Circ Res 48: 309319, 1981.

WEBER KJ: Targeting pathological remodeling. Concepts of cardioprotection and reparation. Circulation 102: $1342-$ $1345,2000$.

WILLIS LR, BAUER JH: Aldosterone in the exaggerated natriuresis of spontaneous hypertensive rats. Am J Physiol 234: F29-F35, 1978.

WU JN, BERECEK KH: Prevention of genetic hypertension by early treatment of spontaneously hypertensive rats with the angiotensin converting enzyme inhibitor captopril. Hypertension 22: 139-146, 1993.

YAMAZAKI J, FUJITA N, NAGAO T: $\mathrm{N}^{\mathrm{G}}$-monomethyl-L-arginine-induced pressor response at developmental and established stages in spontaneously hypertensive rats. J Pharmacol Exp Ther 259: 52-57, 1991.

ZICHA J, KUNEŠ J: Ontogenetic aspects of hypertension development: analysis in the rat. Physiol Rev 79: 1227-1282, 1999. 